\title{
Optimization of the drilling parameters in low angle wells by the application of statistical analysis
}

\author{
Romel Erazo-Bone, MSc. ${ }^{1,2}$, Kenny Escobar-Segovia, MSc. ${ }^{1,3}$, Danilo Arcentales-Bastidas, MSc. ${ }^{1}$, Xavier Vargas- \\ Gutiérrez, MSc, Álvaro Arreaga-Arévalo, Ing. ${ }^{1}$, Adriana Román-Aguilar, Ing. ${ }^{1}$ \\ ${ }^{1}$ Escuela Superior Politécnica del Litoral, ESPOL, Campus Gustavo Galindo Km 30,5 Vía Perimetral, Guayaquil, Ecuador \\ ${ }^{2}$ Universidad Estatal Península de Santa Elena. \\ ${ }^{3}$ Universidad Espíritu Santo - Ecuador \\ kescobar@espol.edu.ec,raerazo@espol.edu.ec,daanarce@espol.edu.ec,alhoarre@espol.edu.ec,adriroma@espol.edu.ec
}

\begin{abstract}
In drilling wells of two sections with a low angle in Tiputini Field-Block 43, have been implemented several hole cleaning practices, handling of different drilling parameters and drilling fluid properties in order to get an optimal hole cleaning. This study pretends to determinate and propose the operational ranges of each parameter involved in drilling and hole cleaning through statistical analysis using the main variables that participate during the drilling and cuttings transport in the intermediate section of $12 \frac{1 / 4}{4}$ " in the next wells with similar characteristic. For the variable selection that will use in the statistic study, it was considered three operational aspects: drilling, drilling fluid and hole cleaning. By means of statistic analysis was determined a regression model that fits the data and describe its behavior. In addition, it was made comparative graphs with each variable, determining the effect of drilling time in each formation. It was statistically determined that the drilling parameters that have the greatest influence in hole cleaning are the gallonage and ROP which will help to optimize the drilling operation of new wells.
\end{abstract}

Keywords: Drilling wells; low angle; statistic analysis; regression model; hole cleaning; gallonage; ROP.

\section{INTRODUCTION}

The oil drilling well inside a new field involves high operational risk, for this reason, is necessary to know the geological data and the ranges of the drilling parameters of the wells that have been drilled near fields to program the drilling project.

Each location is a different scenery and its developing goes reaching a learning curve with the intention of improving continually the indicated practices within the same field.

By the experience is showed that programs of drilling and hole cleaning in Tiputini Field-Block 43 have been constantly modified.
According to the well drilled in Tiputini Field-Block 43, the drilling parameters and drilling fluid properties were modified and was implemented different hole cleaning practices to reach optimal cleaning during the drilling. This study pretends determinate and propose the operational ranges of the parameters associated to the drilling and hole cleaning through a statistic analysis of the variables that have the most influence during the drilling, to optimize the drilling and hole cleaning during the drilling of the intermediate section of $12 \frac{1 / 4}{}$ " in the next wells with similar characteristics.

With the modifications and implementations realized in the next wells, the drilling times and trip times changed, thus, is necessary a performing of a technical - statistic analysis to evaluate and justify the hole cleaning optimization practices, identifying statically the drilling parameters, drilling fluid properties and hole cleaning practices that contribute more to operations optimization, and then estimate its optimal ranges.

The drilling parameters associated with the hole cleaning in two section wells in Tiputini Field-Block 43. Are constantly modified with the intention of getting an optimal cleaning; however, has not been found a study that has a technical and statistic evaluation of this parameters medication and verifies if its values are the most adequate or exist the possibility of reach the optimum.

\section{THEORICAL FRAMEWORK}

An inadequate hole cleaning can carry serious problems during the drilling, problems as a pack-off, high torque and drag; accelerate bit wear, increasing of ROP, inefficiency in measuring tools, fails in drillstring assembly and possibly a well loss.

The improving of hole cleaning practices thought the development of correlations to predict the cuttings volumetric concentration in the annulus and a dimensional analysis related with the ratio between the cutting bed height and the hole diameter[1].

Digital Object Identifier (DOI):

http://dx.doi.org/10.18687/LACCEI2019.1.1.78

ISBN: 978-0-9993443-6-1 ISSN: 2414-6390

$17^{\text {th }}$ LACCEI International Multi-Conference for Engineering, Education, and Technology: "Industry, Innovation, And 
Ogunrinde y Dosunmu, (2012) developed a model that ensure an appropriate hole cleaning in the critical inclination interval $\left(45^{\circ}-60^{\circ}\right)$ and was determined the optimal flow and ROP to reach a successful drilling [2].

During drilling operations is necessary to know the behavior of their parameters that let the progress of the drilling according to the formation that is breached. The main drilling parameters are rate of penetration (ROP), rotation (RPM), weight on bit (WOB), torque (T), flow or gallon per minute (GPM).

The main drilling fluid properties are density, plastic viscosity (PV), yield point (YP), gels, thixotropy, lubricity, cake, filtrate, $\mathrm{pH}$ level.

By an optimal hole cleaning can be obtained a good cutting removal that are created during drilling, it means, the fluid in set with the drilling parameters are able of suspend the solid particles and transport with enough energy outside the well [5]. To avoid problems as packoff, formation fracture, increasing of torque and drag, decreasing of ROP, difficulties to get logs, to run casing and to cement [3].

Cuttings inside annular are subjected to three forces as you can see in the figure 1: one down due to gravity, and other up due to the buoyancy, and the last one parallel to the flow direction due to viscous drag, and all these lead to a helical path.

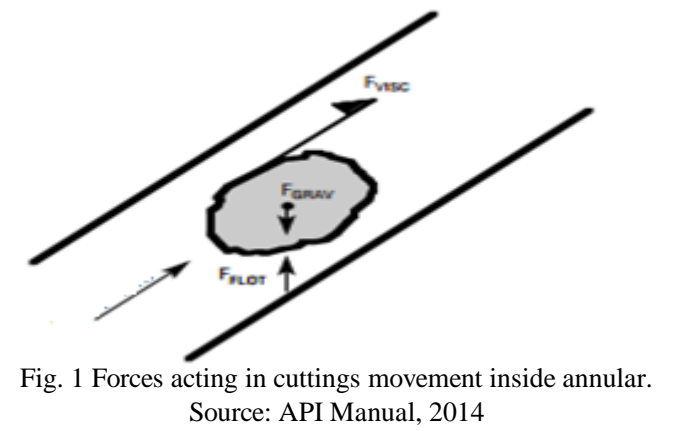

In wells that have an angle less than $15^{\circ}$, the cuttings concentration is just a bit more than vertical wells; between $15^{\circ}$ and $30^{\circ}$, the cuttings concentration changes gradually according to inclination increasing; between $30^{\circ}$ and $60^{\circ}$ can be considered a critical interval due to cuttings concentration increases considerably; for a $45^{\circ}$ inclination. The experience indicates that the cuttings try to stay static by its forces' vector layout (almost totally compensated if there is not an enough annular velocity); and between $60^{\circ}$ and $90^{\circ}$, the formation of cuttings bed is inevitable as you can see in figure 2 .

\section{Hole cleaning indicators}

Exist different ways to program, to monitor and to evaluate a hole cleaning.
The programming was made with simulators, considering the objectives of the well to be drilled and the parameters limitations to handle.

The field monitoring can be made through a virtual hydraulic in real time and ECD control in time and depth through different tools that measure the pressure drop in the annular during drilling, or with values reached by different operation segments in the rig (bits, directional, mudlogging, etc.)[4].

A cleaning evaluation can be performed by monitoring torque and drag curves during and after drilling, mainly in the trips and casing running [5].

The present study will have a focus in drilling indicators during the operations, in this case will be used the ECD as the main hole cleaning indicator [6].

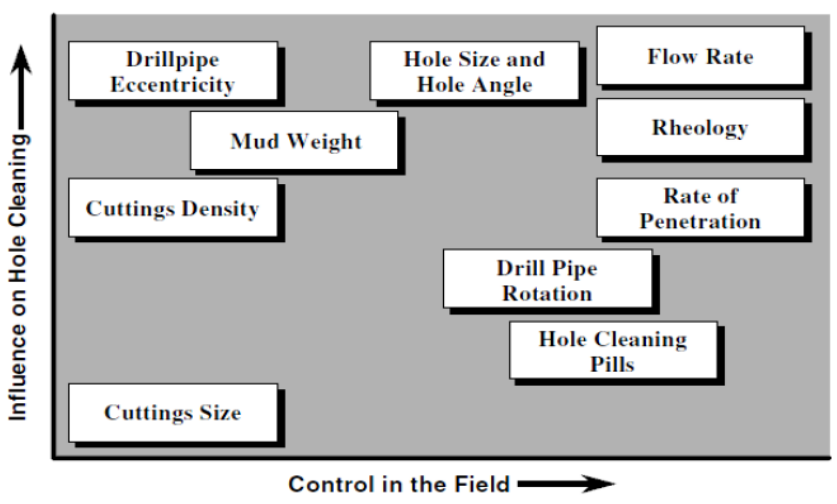

Fig. 2 Hole cleaning factors with the greatest influence

In addition, multivariable regression is implemented with parameters associated to the hole cleaning under values obtained in experimental events to get the relation between each parameter and to generate the optimal ranges to drill.

\section{STATE OF THE ART}

\section{a) Population and sample:}

The used population for this study has several drilled wells in three section in Tiputini Field-Block 43, which report conductor section with $600 \mathrm{ft}$ in depth, and are not considered for hole cleaning study; therefore, these wells will be studied as two sections wells: one intermediate section of $12 \frac{1 / 4}{4}$, and one production section of $8 \frac{1}{2}$ ',

The intermediate section is the section with the greatest importance in the study. 
The sample is conformed by six wells in total: TPTA 021, TPTA 022, TPTA 024, TPTC 007, TPTC 009 and TPTC 010; the first three wells come from PAD A, and the last three come from PAD C.

\section{b) Sample choice:}

The six mentioned wells have been chosen as sample considering the following three criteria:

Criteria 1: conductor section of 16 " ends in $+/-600 \mathrm{ft}$.

Criteria 2: these wells have an intermediate section of $12 \frac{1 / 4}{4}$, and a production section of $81 / 2$ ',

Criteria 3: the $12 \frac{1 / 4}{4}$ ' section has the greatest part of the well, about $4000 \mathrm{ft}$ and therefore crosses the most critical formation during drilling: Indiferenciado, Orteguaza, Tiyuyacu and Tena.

There were 13 wells initially, then the sample was reduced to six wells due to mentioned criteria; it can be appreciated in the following table 1:

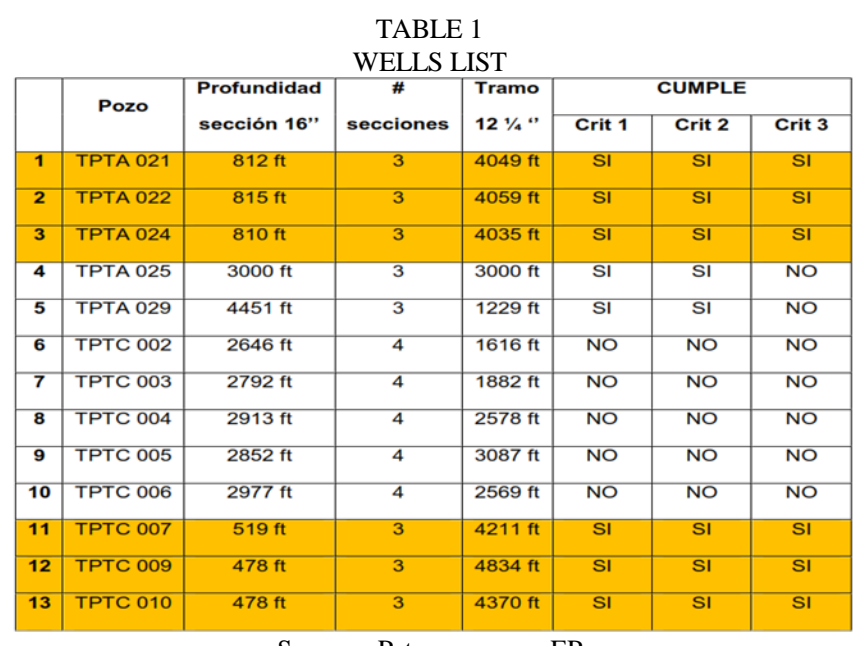

Sources: Petroamazonas EP

\section{c) Variables choice:}

In the variables choice was considered three operational aspects: drilling, drilling fluid and hole cleaning.

The variables related with drilling are rotation (RPM), rate of penetration (ft/hr), and flow (GPM); these parameters were chosen due to these have the greatest influence in drilling process and cleaning.

The variables related with drilling fluid were grouped as drilling fluid properties and are: density (ppg), yield point (lbf/100 ft2), plastic viscosity (cp), GEL 10 SEC (lbf/100 ft2), $10 \mathrm{MIN}$ $(\mathrm{lbf} / 100 \mathrm{ft} 2)$ y $30 \mathrm{MIN}(\mathrm{lbf} / 100 \mathrm{ft} 2)$; in the same way, these variables were chosen due to these have the greatest influence in cutting transport process.

The subtraction between ECD and the drilling fluid density is selected as a cleaning indicator.

\section{d) Data compilation:}

The drilling parameters, drilling fluid properties and the used data for the ECD calculating were obtained from final drilling reports.

\section{e) Data organization:}

For each of the 6 wells was performed a general table, which has the data of top and base formation, its lithology, BHA, drill pipe and hole diameter to be drilled, drilling and trip time, average of ROP and trip velocity.

The drilling parameters, drilling fluid properties and the difference between ECD and drilling fluid density were organized by each well.

\section{f) Data statistic analysis:}

The ROP values are smoothed to eliminate the abrupt changes. Then, the atypical values test was performed for each one of the variables. If atypical values appear, these should be eliminated; and then a correlation matrix is calculated to identify how related are the variables with others. A normality test is also performed to know if the data has a normal behavior; in case that the data does not have normal behavior, is performed a Box-Cox transformation to adjust the data [6].

\section{g) Linear multiple regression model choice:}

As a first instance, a response surface design must be created, for which variables and factors are loaded in MINITAB 18 software, note that each factor will be continue.

Several models were performed for each formation, and the best data adjusting was chosen. The theorical fundament must be appreciated in the model. According to the chosen model is going to be made the optimization [7].

\section{h) Hole cleaning Optimization:}

The wanted responded variable is determined with a dispersion graph to identify an average operating range; also, top and base formation is determined as well as initial and final density.

$17^{\text {th }}$ LACCEI International Multi-Conference for Engineering, Education, and Technology: "Industry, Innovation, And Infrastructure for Sustainable Cities and Communities", 24-26 July 2019, Jamaica. 
Due to GEL 30 MIN is related with GEL 10 MIN, is used a regression model to determinate the initial and final values of GEL 30 MIN through obtained GEL 10 MIN values.

\section{EXPERIMENTAL DEVELOPMENT}

Statistically a design of experiments is a good researching tool that allows evaluating the dependence between input variables (factors) and a response variable trough equations or mathematical models [8].

A design of experiment also is used to identify conditions process and the factors or components that affect to this, for later determinate the factor configurations that optimize the results. There are several designs of experiments, for example: Exploration, Factorial, Response Surface, Mixture and Taguchi.

In the Response Surface design, the input variables can be continuous or discrete [9].

\section{Statistic tools for variables analysis:}

Before any statistic study is necessary trying the data, this study used MINITAB 18 software that has the following tools:

Atypical values test: contribute to identify values in the sample that do not represent the population.

Correlation Matrix: through a coefficient between -1 and 1 is measured how related are two variables, this coefficient indicates the direction and magnitude of the relation.

Box - Cox transformation: fit the data of the variables to a normal distribution through a power.

\section{RESULTS}

\section{Indeferenciado Formation:}

A model with an adjust of $\mathrm{R}^{2}$ of $94.82 \%, \mathrm{R}^{2}$ adjusted of 94.39 $\%$ and a $\mathrm{R}^{2}$, prediction $92.86 \%$ was gotten.

The terms of the model do not present a high FIV that is interpreted as a stable model [10].

The residue graph of the model is illustrated in the figure 3 and this shows that the assumption of the model was reached.

In addition, the showed Pareto Chart in the figure 3 indicates that the effect of variables on the response variable goes according to the theory, which ensure the using of the model; also, the effect of drilling fluid properties can be appreciated in the response variable.

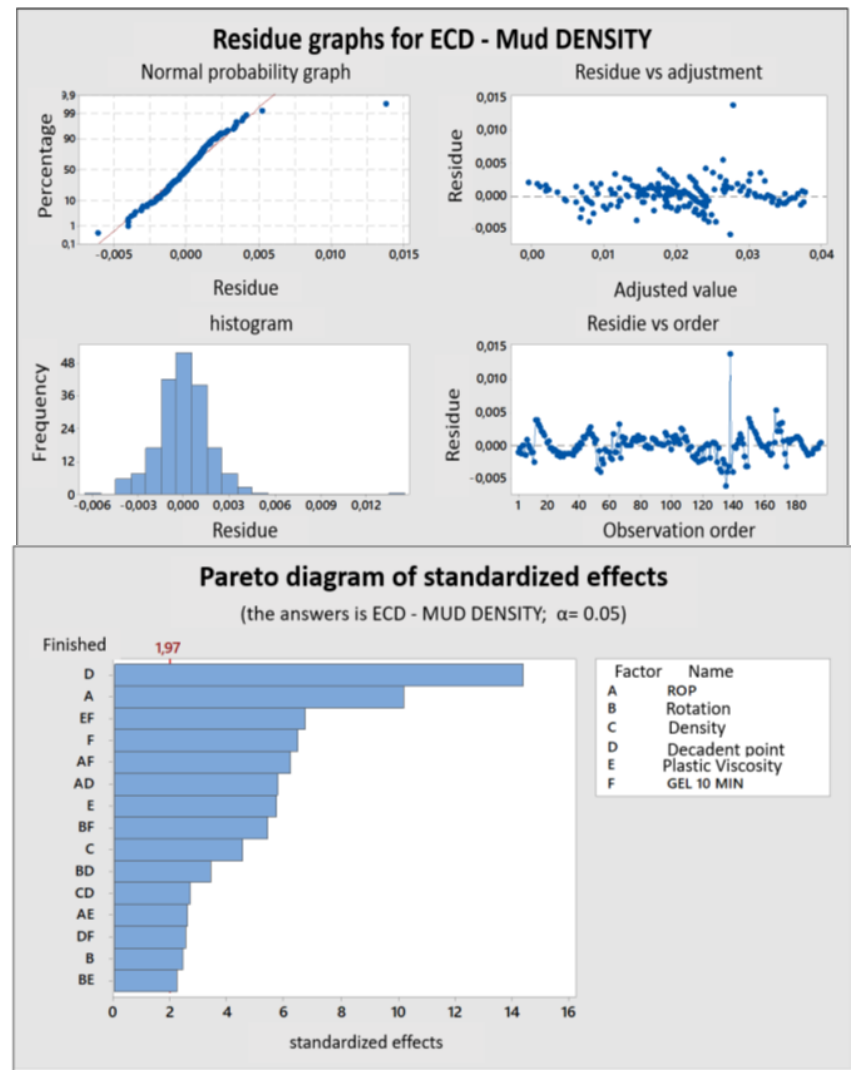

Fig. 3 Residual plot and Pareto diagram for the model used in the training Undifferentiated

In the figure 3, the main effects of each one of the variables on the response variable are shown. The trends of the variables are technically correct.

\section{Tena Formation:}

This formation shows a combination of several designs of experiments, one for drilling parameters and other for drilling fluid properties. Both models are stable.

In the showed Pareto Charts in figure 4 is appreciated the effect of parameters interaction.

These interactions work with a level to associate the behavior of two variables with the response variable.

In the diagram to the top side in the figure 4 is appreciated the effect of the density is not significant, but this parameter is taken to adjust the geomechanics conditions of the formation to each density value.

$17^{\text {th }}$ LACCEI International Multi-Conference for Engineering, Education, and Technology: "Industry, Innovation, And Infrastructure for Sustainable Cities and Communities", 24-26 July 2019, Jamaica. 
The diagram to the down side corresponds to the model that uses drilling parameters, is not appreciated the effect of flow; despite of being technically incorrect, will be taken due to the nature of data.

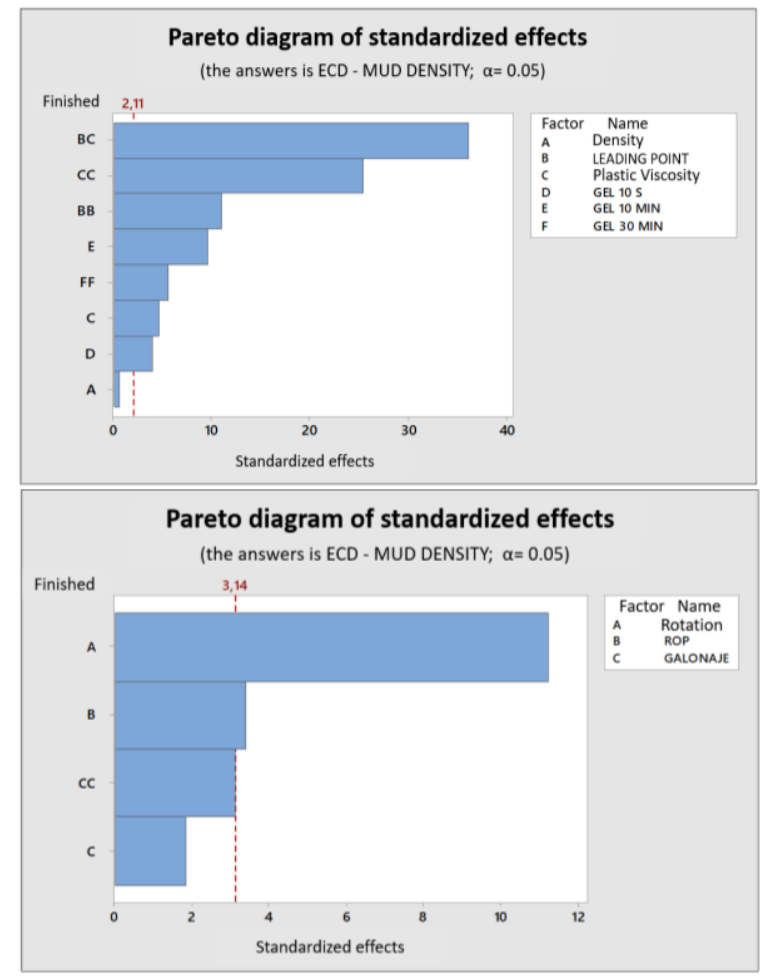

Fig. 4 Pareto diagram of the models used in the Tena formation

The main effects chart for both models are technically correct, except the flow variable that has not major influence in the response variable. See fig. 5 .

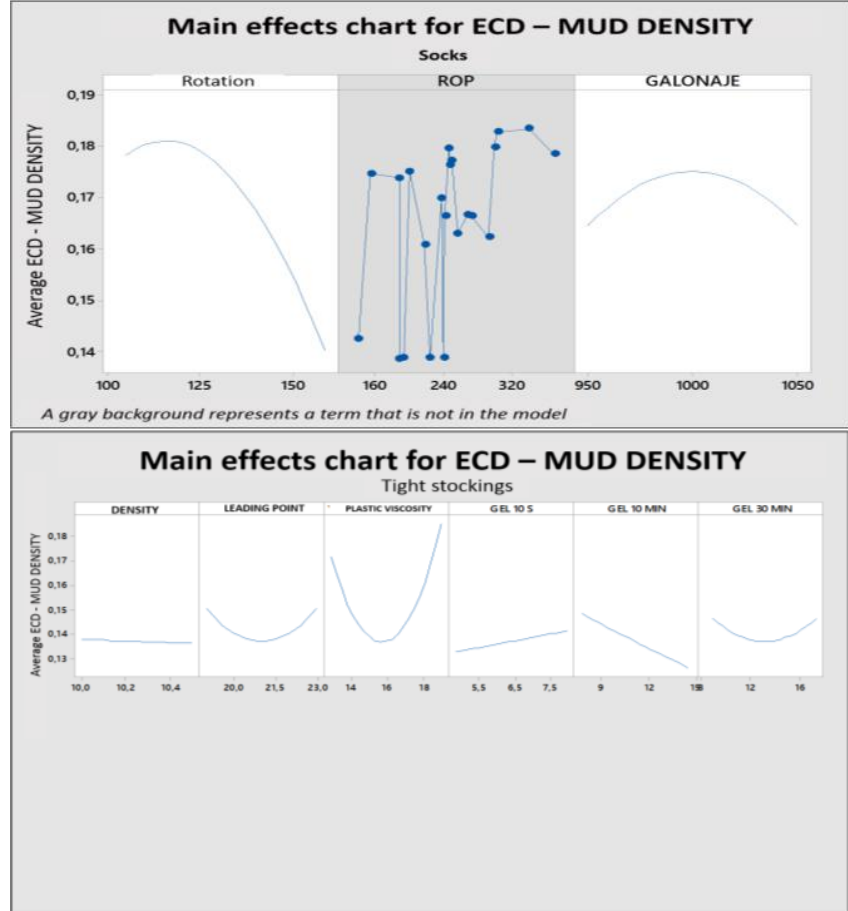

Fig. 5 Graph of effects of the models used in the Tena formation

\section{RESULT ANALYSIS}

\section{Indiferenciado Formation:}

Drilling parameters and drilling fluid properties were taken every $100 \mathrm{ft}$ to have a better drilling and hole cleaning optimization. It is shown in table 2.A rotation of 50 RPM from $500 \mathrm{ft}$ to $1600 \mathrm{ft}$ is proposed, which can be reached by slipping in case of mud motor. Later in $1600 \mathrm{ft}$, goes increasing the rotation to allow the cuttings beds removal, values between 117 and 165 RPM could be reached with rotation. 
TABLE 2

OPTIMUM OPERATING RANGES OF DRILLING PARAMETERS AND DRILLING FLUID PROPERTIES IN THE INDIFERENCIADO FORMATION

\begin{tabular}{|c|c|c|c|c|c|c|c|c|c|c|c|}
\hline \multirow{3}{*}{$\begin{array}{c}\text { DEPTH } \\
\text { (MD) }\end{array}$} & \multicolumn{3}{|c|}{ DRILL PARAMETERS } & \multicolumn{6}{|c|}{ PROPERTIES OF PERFORATION FLUIDS } & \multirow[b]{2}{*}{$\begin{array}{c}\text { ECD - LODO } \\
\text { DENSITY }\end{array}$} & \multirow[b]{2}{*}{$\begin{array}{l}\text { Drilling } \\
\text { time }\end{array}$} \\
\hline & ROTATION & & GALLONAGE & DENSITY & $\begin{array}{l}\text { LEADING } \\
\text { POINT }\end{array}$ & $\begin{array}{c}\text { PLASTIC } \\
\text { VISCOSITY }\end{array}$ & GEL 10 SEG & GEL 10 MIN & GEL 30 MIN & & \\
\hline & [RPM] & [ft/hr] & [GPM] & & [lbf/100ft2] & [cP] & [lbf/100ft2] & [lbf/100ft2] & [lbf/100ft2] & [ppg] & [hora] \\
\hline [ft] & Optimum & Optimum & Optimum & [ppg] & Optimum & Optimum & Optimum & Optimum & Optimum & Optimum & Optimum \\
\hline 500,00 & 50,00 & 300,00 & 937,90 & 8,90 & 3,03 & 2,01 & 1,93 & 3,02 & 2,41 & 0,01 & 0,33 \\
\hline 600,00 & 50,00 & 400,00 & 1059,25 & 8,93 & 3,03 & 2,01 & 1,93 & 3,02 & 2,41 & 0,01 & 0,25 \\
\hline 700,00 & 50,00 & 596,91 & 1204,65 & 8,95 & 4,17 & 2,53 & 2,29 & 3,33 & 2,94 & 0,03 & 0,17 \\
\hline 800,00 & 50,00 & 593,63 & 1203,25 & 8,98 & 4,75 & 3,06 & 2,61 & 3,63 & 3,44 & 0,03 & 0,17 \\
\hline 900,00 & 50,00 & 590,00 & 1201,66 & 9,01 & 5,32 & 3,58 & 2,85 & 3,94 & 3,95 & 0,04 & 0,17 \\
\hline 1000,00 & 50,00 & 587,00 & 1200,30 & 9,04 & 5,89 & 4,10 & 3,05 & 4,25 & 4,46 & 0,05 & 0,17 \\
\hline 1100,00 & 50,00 & 584,02 & 1198,93 & 9,06 & 6,46 & 4,63 & 3,21 & 4,55 & 4,94 & 0,05 & 0,17 \\
\hline 1200,00 & 50,00 & 579,47 & 1196,79 & 9,09 & 7,03 & 5,15 & 3,33 & 4,86 & 5,43 & 0,06 & 0,17 \\
\hline 1300,00 & 50,00 & 563,24 & 1188,59 & 9,12 & 7,61 & 6,20 & 3,49 & 5,17 & 5,91 & 0,06 & 0,18 \\
\hline 1400,00 & 50,00 & 551,77 & 1182,28 & 9,15 & 7,69 & 6,29 & 3,50 & 5,52 & 6,45 & 0,06 & 0,18 \\
\hline 1500,00 & 50,00 & 536,52 & 1173,25 & 9,17 & 8,73 & 6,72 & 3,55 & 6,09 & 7,30 & 0,07 & 0,19 \\
\hline 1600,00 & 50,00 & 524,11 & 1165,35 & 9,20 & 9,32 & 7,24 & 3,60 & 6,39 & 7,73 & 0,07 & 0,19 \\
\hline 1700,00 & 163,60 & 509,31 & 1155,29 & 9,23 & 9,89 & 7,77 & 3,65 & 6,70 & 8,18 & 0,08 & 0,20 \\
\hline 1800,00 & 98,00 & 502,62 & 1150,51 & 9,25 & 10,46 & 8,29 & 3,71 & 6,70 & 8,18 & 0,08 & 0,20 \\
\hline 1900,00 & 140,36 & 482,83 & 1135,54 & 9,28 & 11,04 & 8,81 & 3,79 & 7,00 & 8,60 & 0,08 & 0,21 \\
\hline 2000,00 & 117,67 & 460,22 & 1116,89 & 9,31 & 11,04 & 9,34 & 3,89 & 7,31 & 9,03 & 0,08 & 0,22 \\
\hline 2100,00 & 50,00 & 448,56 & 1106,63 & 9,34 & 11,61 & 10,25 & 4,13 & 7,62 & 9,45 & 0,08 & 0,22 \\
\hline 2200,00 & 164,74 & 415,83 & 1075,52 & 9,36 & 12,18 & 10,38 & 4,18 & 7,92 & 9,84 & 0,08 & 0,24 \\
\hline 2300,00 & 165,91 & 400,00 & 1059,25 & 9,39 & 13,32 & 11,24 & 4,55 & 8,54 & 10,65 & 0,08 & 0,25 \\
\hline 2400,00 & 165,91 & 400,00 & 1059,25 & 9,42 & 13,90 & 11,95 & 4,97 & 8,84 & 11,02 & 0,08 & 0,25 \\
\hline 2500,00 & 165,91 & 400,00 & 1059,25 & 9,45 & 13,90 & 12,47 & 5,36 & 9,15 & 11,40 & 0,07 & 0,25 \\
\hline 2600,00 & 165,10 & 300,00 & 937,90 & 9,50 & 14,47 & 13,00 & 5,82 & 9,45 & 11,76 & 0,06 & TOTAL 4,37 \\
\hline
\end{tabular}

An initial and final velocity of $300 \mathrm{ft} / \mathrm{hr}$ was used to ensure the directional plans. The rest of points were optimized with high ROP to benefit the drilling without harming the cleaning. While the optimized ROP values are taken, immediately minimum ECD - mud density values are being sought that are inside the operational range [11].

Flow was high, which is adequate to transport cuttings to surface and reduce the annular cuttings load.

Flow values are not fixed but could be performed a practice with fixed values as 1000 GPM, 1500 GPM or 1200 GPM according to what was reached.

Density was not optimized in the model, because was only used as a depth indicator. In figure 6, the type of gel proposed is flat

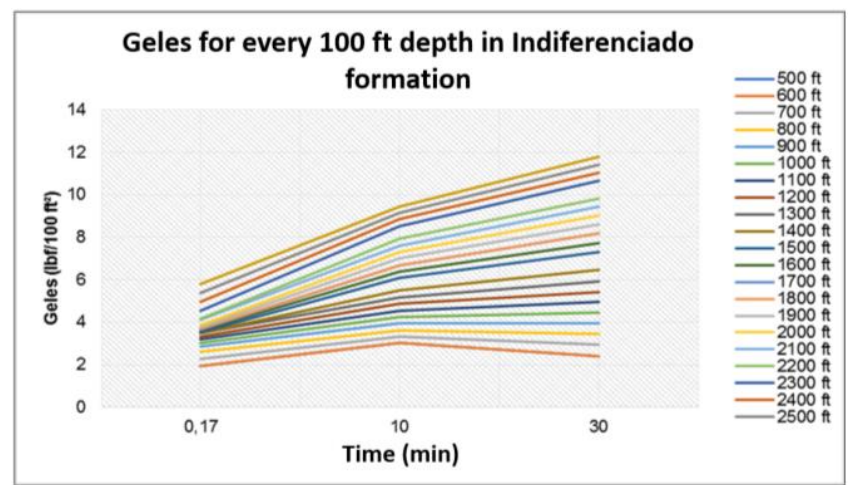

Fig. 6 Gels in the Indiferenciado formation
10 SEC GEL has a rising trend according to the depth. Due to this property was correlated with the plastic viscosity, was possible to get initial values below the used ones until the first $300 \mathrm{ft}$.

This study in not excluded but must be subject to experienced technical criteria.

10 MIN GEL in the most important property in cleaning after plastic viscosity. Its values were directly optimized by design of experiments. Rising values were reached and reduced in range, which technically is appropriated in operations.

30 MIN GEL were determined by 10 MIN GEL regression; its values are inside handled ones and have a rising trend while get drilling.

\section{Tena Formation:}

Table 3 shows the ranges of the parameters that should be handled to optimize drilling and cleaning in Tena formation.

$17^{\text {th }}$ LACCEI International Multi-Conference for Engineering, Education, and Technology: "Industry, Innovation, And Infrastructure for Sustainable Cities and Communities", 24-26 July 2019, Jamaica. 
TABLE 3

OPTIMUM OPERATING RANGES OF DRILLING PARAMETERS AND DRILLING FLUID PROPERTIES IN THE TENA FORMATION

\begin{tabular}{|c|c|c|c|c|c|c|c|c|c|c|c|}
\hline \multirow{3}{*}{$\begin{array}{c}\text { DEPTH } \\
\text { (MD) }\end{array}$} & \multicolumn{3}{|c|}{ DRILL PARAMETERS } & \multicolumn{6}{|c|}{ PROPERTIES OF PERFORATION FLUIDS } & \multirow[b]{2}{*}{$\begin{array}{l}\text { ECD-1000 } \\
\text { DENSTIY }\end{array}$} & \multirow[b]{2}{*}{$\begin{array}{c}\text { Drilling } \\
\text { time }\end{array}$} \\
\hline & & & & DENSTYY & $\begin{array}{l}\text { LEADING } \\
\text { POINT }\end{array}$ & $\begin{array}{c}\text { Plastic } \\
\text { Viscosity }\end{array}$ & GEL 10 SEG & GEL $10 \mathrm{MIN}$ & GEL 30 MIN & & \\
\hline & [RPM] & [Tht] & [GPII] & & 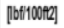 & [CP] & [btf1000t2] & [lbfil100tel] & pbfi1000t2] & [ppg] & [hora] \\
\hline [it] & Optimum & optimum & optinum & [ppg] & Optimum & Optetum & optenum & Oostinum & optimum & Ootimum & optemum \\
\hline 4400,00 & 150,00 & 370,00 & 1000,00 & 10,20 & 19,00 & 12,90 & 4,83 & 7,71 & 10,19 & 0,15 & 0,27 \\
\hline 4500,00 & 100,00 & 370,00 & 1000,00 & 10,23 & 19,00 & 13,60 & 4,83 & 8,31 & 10,91 & 0,14 & 0,27 \\
\hline 4000,00 & 150,00 & 363,16 & 96000 & 10.25 & 1975 & 14,36 & 523 & 8.92 & 11.64 & 0,14 & 0.28 \\
\hline 4700,00 & 150,00 & 363,16 & 900,00 & 10.28 & 20.25 & 14,80 & 5,82 & 9,37 & 1236 & 0,14 & 0.28 \\
\hline 4800,00 & 150,00 & 363,16 & 960,00 & 10,30 & 20,75 & 15,56 & 6,2 & 9.82 & 1247 & 0,14 & TOTAL 1,10 \\
\hline
\end{tabular}

Approximate input and output values of the formation were maintained, with the average of those managed according to geology reports.

The optimization suggests a rotation of 150 RPM in almost all the interval to reach the objectives. This rotation can be achieved with rotation throughout all formation. It is essential not only to achieve rotation to remove cuttings to the flow stream, it also contributes to reach an effective and adequate ROP.

The results show that it is possible to achieve high ROPs that are not often handled and with an adequate control of the ECD - MUD DENSITY.

A gallonage between 960 and 1000 GPM is required, no more than this. One higher could be used to further reduce the annular load, but here an increase of the ECD could occur, not by accumulated cuttings, but because of the loss of pressure due to a turbulent flow.

It was possible to optimize the yield point with increasing values of this property and in reduced ranges to those used. You can see a rising trend of plastic viscosity and reduced that do not depend on excessive pumping flow while operations are interrupted.

Gels carry a rising trend as it deepens and with a lower operating range than those handled. The 10 MIN GEL is the most important property in cleaning according to the model described in this formation. Their values were optimized directly from the design of experiments. The 30 MIN GEL values were calculated directly by the model despite the correlation with 10 MIN GEL, are within the handled but reduced their maximum values since the wells are of low angle and therefore do not require a wide range of this property for an efficient hole cleaning. In figure 7, the type of gel proposed is flat.

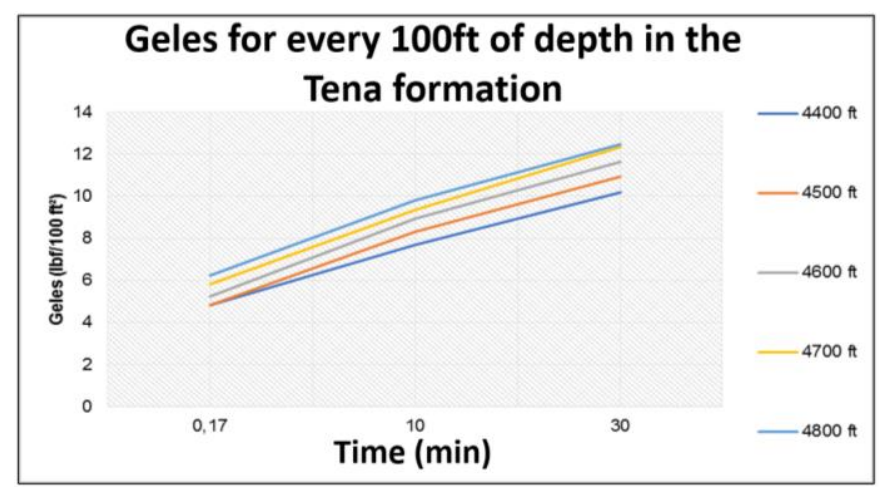

Fig. 7 Gels in the Tena formation

The proposed values of the optimization for the FLOW, ROP factors are increased in most of the 12 1/4 "section.

For ROTATION factor, its values are reduced in most of the Indiferenciado formation, while for the other formations the optimized values have no significant difference with respect to the values handled.

YIELD POINT factor is maintained in the Indiferenciado formation and a reduction of its values is proposed for drilling of the next formations.

In most of the section, the values of plastic viscosity factors and gels are reduced to achieve cleaning optimization, shows it in the figure 8,9 and 10 .

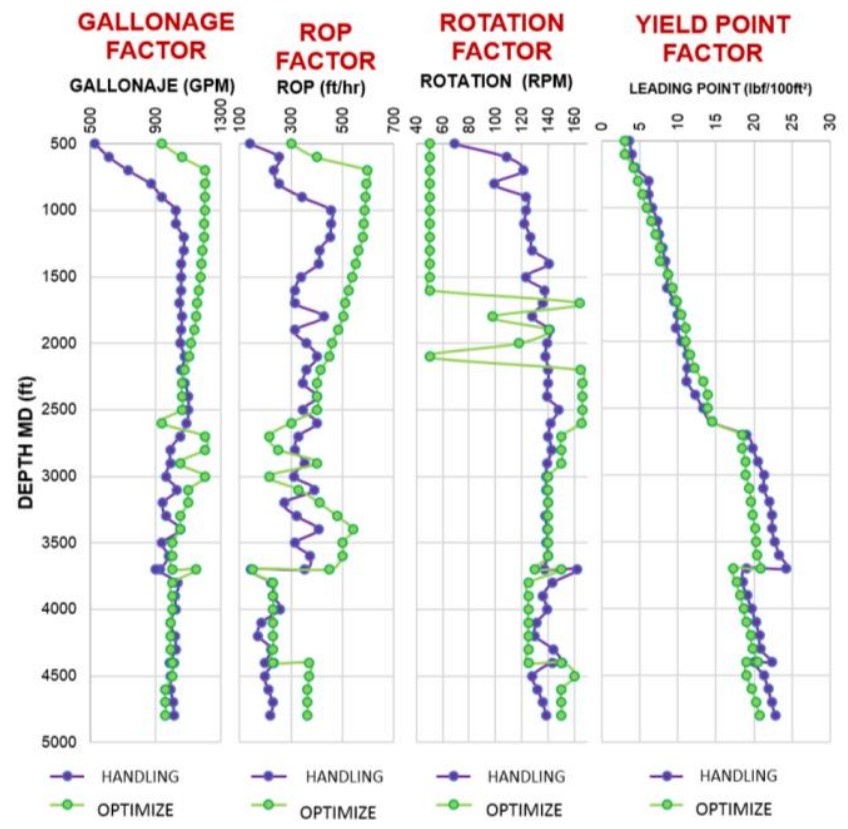

Fig. 8 Managed and optimized values for gallonage, ROP, rotation and yield point.

$17^{\text {th }}$ LACCEI International Multi-Conference for Engineering, Education, and Technology: "Industry, Innovation, And Infrastructure for Sustainable Cities and Communities", 24-26 July 2019, Jamaica. 


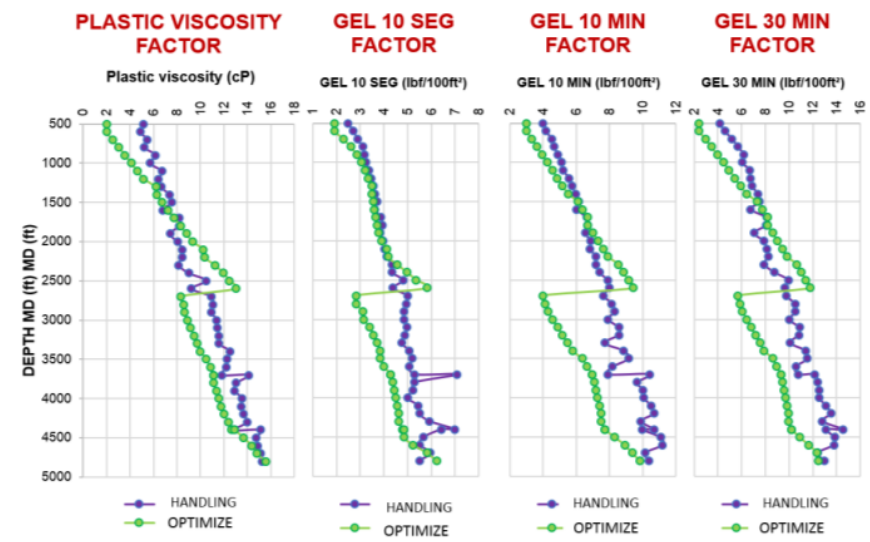

Fig. 9 Comparison of manipulated and optimized values of plastic viscosity and gels

Comparison between density difference and drilling times:

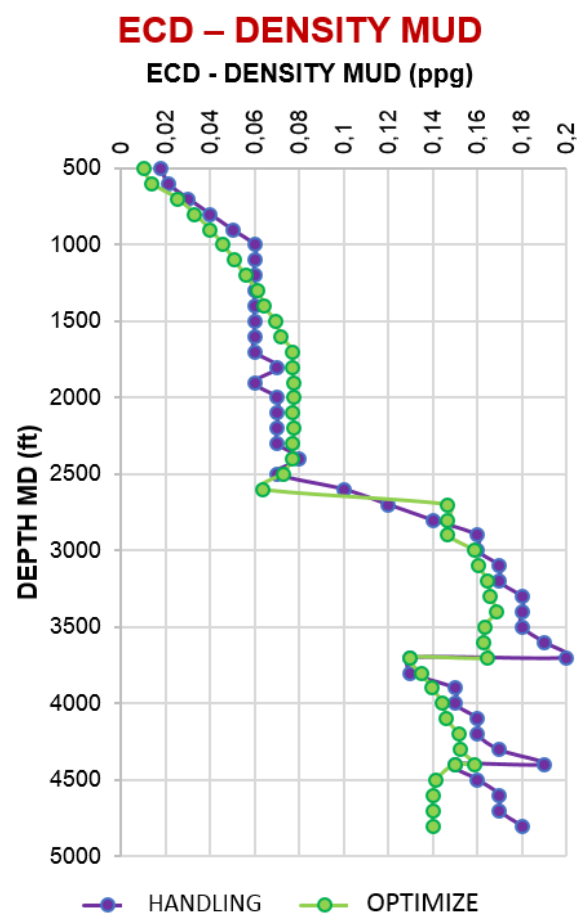

Fig. 10 Comparison of the difference of managed and optimized densities

It is observed that the values optimized in most formations do not exceed the values handled, except for the last $1400 \mathrm{ft}$ of the Indiferenciado formation. This proposal has to keep a technical criteria of geomechanics due to there is no knowledge of the maximum allowed ECD in this section.

Figure 11 shows the drilling times that had in the operations in each well and the drilling times that would had to the proposed optimizations.

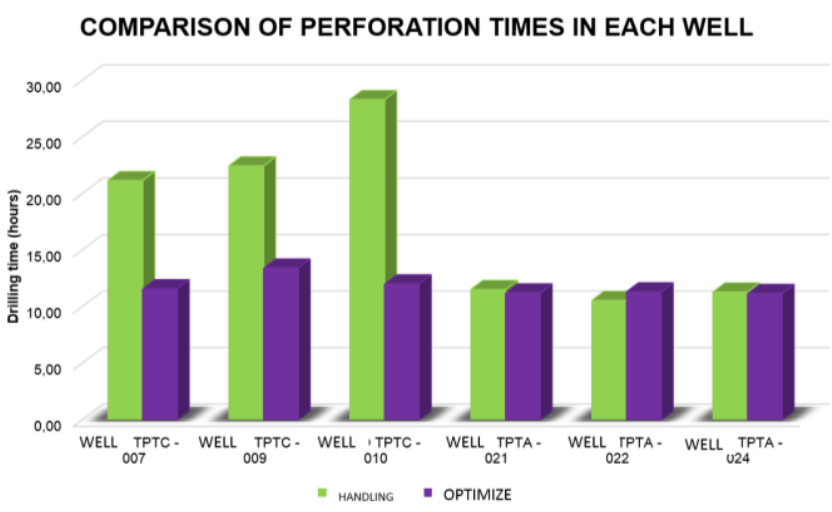

Fig. 11 Comparison of drilling times

It is observed that in the wells of pad $\mathrm{C}$, the drilling time is considerably reduced, while in the pad A there is no significant difference.

Analysing the averages of the factors handled in the 6 wells of the sample, a drilling time of 15 hours is obtained, while applying the optimizations proposed, the drilling time is 12 hours, therefore, when applying the ranges of the parameters proposed by each formation will get a $20 \%$ reduction in drilling time [12].

\section{CONCLUSIONS}

Because the drilling parameters and drilling fluid properties are not programmed for different points in the trajectory of a formation, the statistical study of the results obtained in wells with similar geometric and geological conditions is adequate to propose values for each certain depth drilled that optimize the hole cleaning and reduce the drilling times.

In low angle, wells such as those worked in this study. Fluid properties such as yield point, plastic viscosity and gels are the most important and critical factors in hole cleaning, followed by the flow, ROP and rotation; this goes with the results obtained in the statistical study, and with this, the terms related to the properties of the fluid show the lowest $p$ values in each of the models used.

The drilling parameters that most influence the hole cleaning are flow and ROP. The first one generates the transport force of the cuttings to the surface and the second one the cuttings generation rate in the hole.

Because the wells studied are of low angle, the rotation does not have a significant effect on the cleaning while drilling, which is also checked in the effect graphs of each model. The rotation factor will only be influential while performing re-entry practices while drilling to allow the removal of cuttings that have remained seated in the hole. 
An adequate hole cleaning for low angle wells as those used in the study, show that high yield points, low viscosities and flat gels are necessary, and with this, these parameters can decrease the sliding rate of the cuttings, reduce excessive pressures of pumping and suspend the cuttings while the circulation of the fluid is interrupted.

As the depth increases, the cuttings generated tend to increase the plastic viscosity if they are not removed properly, therefore, the plastic viscosity should be handled with the lowest possible values to compensate this increase.

Ranges gels have a flat behavior, values with less than 20 pound / $100 \mathrm{ft} 2$ and there is no significant variation in the different times, which avoids using high pumping pressures when the operations are restarted after an interruption.

The optimal combination of drilling parameters and fluid properties of the Indiferenciado formation shows annular velocities greater than the critical, this determines that one of the best practices for hole cleaning is to maintain a turbulent flow as long as it does not compromise the integrity of the formation.

The increase in fluid density contributes to an efficient transport, however, it was not possible to optimize this parameter due to the geomechanical information of the wells was not available to identify the values that could be handled without compromising the integrity of the formation.

The density is a property of the drilling fluid that serves as a guiding factor in the optimization of the other factors; this indicates the capacity of an adequate mud weight in an open hole at a certain depth, which allows to perform an optimization at different points of the trajectory of a section.

The combination of drilling parameters and fluid properties should provide an ECD that is not capable of fracturing the formation, this shows that the ECD, beyond being an indicator of hole cleaning, is a tool to validate that the optimization of cleaning practices are performed without harming the integrity of the well while drilling.

An increase in ROP and flow values is proposed. The increase in ROP decreases the drilling time, and despite increasing the number of cuttings during the operation, the increase in flow favors the transport of these cuttings to the surface, because the annular velocity increases.
With drilling parameters and fluid properties proposed, a reduction in drilling times is obtained compared with each of the wells in the sample. The difference in times of the wells of $\mathrm{Pad} \mathrm{C}$ are greater with respect to those of Pad A because in the latter, high values of rotation, ROP and flow were handled.

With the proposed optimization, the drilling time is reduced by $20 \%$ compared to the average values of the times handled by each well in the section. This reduction in time is mainly due to the wells of Pad C where longer operating times were handled.

\section{REFERENCIAS}

[1] Amanna, B., \& Khorsand, M. (2016). Cutting transport behavior in direccional drilling using computational fluid dynamics. Tehran, Iran: Journal of Natural Gas Science and Engineering.

[2] Ogunrinde, J., \& Dosunmu, A. (2012). Hydraulics Optimization for Efficient Hole Cleaning in Deviated and Horizontal Wells. Choba.

[3] Zhang, F., Miska, S., Yu, M., Ozbayoglu, E., Takach, N., \& Osgouei, R. (2015). Is Well Clean Enough? A Fast Approach to Estimate Hole Cleaning for Directional Drilling. Texas.

[4] Y V Lykov, V G Gorelikov, Baatarkhuu Gantulga, (2017), Analytical research and classification of mechanism of diamond drilling-bits contact with rocks during well sinking, IOP Conf. Series: Earth and Environmental Science, 87, Saint-Petersburg Mining University, 21 Line, No.2, 199106, Saint-Petersburg, Russian Federation

[5] Azar, J., \& Robello, S. (2007). Drilling Engineering. Oklahoma: PennWell Corporation.

[6] Tobenna, U. (2010). Hole Cleaning and Hydraulics. Tesis de maestría, Univrsitetet i Stavanger, Stavanger.

[7] Montgomery, D. (2017). Design of Experiments. Pag. 170 -380, John wiley \& sons

[8] Gorelikov V. G., Lykov Yu. V., Baatarkhuu Gantulga, 2016, Analytical and Experimental Study of the Mechanisms of Diamond Bits Interaction with Rocks in the Wellbore During Sinking Processes, International Journal of Applied Engineering Research ISSN 0973-4562 Volume 11, Number 10 (2016) pp 7012-7016.

[9] Mengjiao, Y., \& Takach, N. (2007). An Experimental Study of Hole Cleaning Under Simulated Downhole Conditions. California.

[10] Piroozian, A., \& Babakhani, P. (2012). Impact of drilling fluid viscosity, velocity and hole inclination on cuttings transport in horizontal and higly deviated wells. Malaysia.

[11] Annis, M., \& Smith, M. (1974). Drilling Fluids Technology.

[12] Fernández, M., \& Romero, J. (2003). Curso básico de perforación direccional.

\section{NOMENCLATURE}

$\begin{array}{lc}\text { RPM: } & \text { Revolutions per minute } \\ \text { Ft / hr: } & \text { Feet per hour } \\ \text { GPM: } & \text { Gallons per minute } \\ \text { Ppg: } & \text { Pounds per gallon } \\ \text { lbf / 100ft2: } & \text { Pounds force per 100 square feet } \\ \text { cP: } & \text { Centipoises } \\ \text { hr: } & \text { Hours } \\ \text { n: } & \text { Rheological coefficient } \\ \theta_{-}(600), \theta_{-} 300: \text { Rheological efforts at } 600 \text { and 300 RPM } \\ \text { K: } & \text { Rheological coefficient }\end{array}$

$17^{\text {th }}$ LACCEI International Multi-Conference for Engineering, Education, and Technology: "Industry, Innovation, And Infrastructure for Sustainable Cities and Communities", 24-26 July 2019, Jamaica. 